\title{
Nachruf
}

\section{Hans Peter Bernet, 1949-2015}

Rony Weissberg (Zürich)

Er fehlt. Noch nie in meinem Leben ist mir dieses Fehlen so aufgefallen wie hier, bei Hampi, diesem Kollegen und Freund: Markant seine Erscheinung, sein Auftritt, sein Sprechen, sein Engagement - über 15 Jahre, zunächst wöchentlich, dann nur noch alle 14 Tage waren wir zusammengekommen, um mit weiteren Kollegen über Psychoanalyse und über unsere Fälle zu sprechen. Ich sehe ihn immer noch, wie er kommt, nicht selten etwas zu spät, wie er eintritt, uns begrüsst und schon ist er mitten in seiner Erzählung, ist von etwas gepackt, fasziniert, muss es uns mitteilen. Und dann, nicht minder deutlich, wie er und ich zusammen aus der Sitzung weggehen, die Olgastrasse zum Bahnhof Stadelhofen runter, immer noch mitten ins Gespräch vertieft und uns dann losreissen, verabschieden. Jetzt ist er weg - für immer. Und bei jedem der folgenden Treffen war klar, er fehlt, er, der fast immer mit seinem ganzen Herz und seiner Leidenschaft mit uns dabei war. Es ist für mich ganz anders als beim Verlust der Eltern, es ist einer mitten aus dem Leben, aus dem Zusammenleben, aus dem gelebten Alltag. Und so ist es vielleicht eine Absurdität des Schicksals, dass Hampi an der Teilnehmerversammlung im letzten Sommer den Nachruf auf Renate Hauser machte, eine Freundin, mit der wir beide zusammen, Hampi und ich, in der Seminarleitung waren, Renate, die ebenso jäh aus unserem Leben verschwunden ist. Es ist dies eine unmittelbare Konfrontation mit dem, was wir alle wissen und doch immer wieder vergessen, zum Teil auch vergessen müssen: die Tatsache des Todes, die Tatsache unserer Sterblichkeit. Vielleicht gibt es nichts, das uns dem näher bringt, als der Verlust eines Kollegen gleichen Alters.

Ich möchte zu seinem Leben und seiner Biografie hier nur einige Andeutungen machen: Aufgewachsen ist er im Prättigau, in Klosters. Doch dem weltoffenen und lebendigen Geist eines Hans Peter war es in diesem Tal rasch zu eng. 
Einen ersten Schritt machte er nach Chur, wo er das Lehrerseminar absolvierte, aber schon bald zog es ihn noch weiter, hierher nach Zürich, wo er Psychologie zu studieren begann und sich intensiv mit der Ethnopsychoanalyse beschäftigte. Dies fällt dann mitten in die 68er- und in dieWG-Zeit, die für Hampi sehr prägend war.

Doch zuvor noch ein, zwei Gedanken: Mit dieser Wegbewegung aus der Heimat muss erwähnt sein, wie sehr er seinem Prättigau doch auch treu und tief verbunden blieb. Deutlich zeigte sich dies an seinem Engagement für den HC Davos. Wann immer er konnte, reiste er an die Spiele des Clubs; Hampi war ein bekanntes Mitglied der Davoser Fan-Gemeinde und beteiligte sich aktiv in den Foren des HCD. Überhaupt ist es so, dass Hampi in verschiedensten Gebieten aktiv und engagiert war, so auch in der Politik, wo er von 1991 bis 1994 Präsident der SP Pfäffikon war oder wie die meisten von Ihnen wissen und erfahren haben: durch seine Mitarbeit und seine Kommentare in der Cinepassion: Ich denke z. B. an seine Besprechung des Films «La flor de mi secreto» von Almodóvar. Noch im Dezember 2015 war vorgesehen gewesen, dass er zusammen mit Alexander Moser «Barry Lyndon» von Stanley Kubrick kommentiert. Wie wir wissen, war das dann nicht mehr möglich.

Ich komme zurück zur Studien- und zur 68er-Zeit in Zürich. In diese Periode fallen zwei wesentliche Entwicklungen seines Lebens: Zum einen gründet er eine Familie. Hampi wird Vater von zwei Töchtern und er wird Psychoanalytiker, und zwar betreibt er diesen Beruf mit seiner ihm eignen Intensität, Leidenschaft und seinem Engagement. Dazu gehörte nicht zuletzt, dass er immer wieder auch Randfiguren behandelte und sich dabei hin und wieder in Naturalien bezahlen liess. Hampi war aber auch ein sehr aktives Mitglied des psychoanalytischen Seminars. Ihm ist viel zu verdanken, zum Beispiel dass es uns gelungen ist, am PSZ eine Ausbildung in Psychotherapie auf die Beine zu stellen, die sowohl in der Charta Anerkennung fand, als auch innerhalb des PSZ unterstützt wurde. Er war auch, wie schon erwähnt, während 4 Jahren in der Seminarleitung und arbeitete u. a. über Jahre hinweg in der Charta-Bestätigungskommission. Zudem: Immer wieder führte er Kurse am PSZ durch, die jeweils auf grosses Interesse stiessen: Erinnern möchte ich hier an einen Kurs zum «normalen und pathologischen Narzissmus» aus dem Jahre 2008 und zuletzt ein zwei-semestriger Kurs im vergangenen Jahr mit dem Titel «Aus dem Blick verlieren», eine Auseinandersetzung mit dem gleichnamigen Buch von Pontalis, ein Buch und ein Autor, das und der ihn sehr faszinierte.

Wir verlieren mit Hans-Peter einen Menschen, der Enormes fürs PSZ leistete und der nicht wenigen von uns viel gab. Aber wir verlieren sicherlich auch einen streitbaren Kollegen, dem seine Affekte da und dort durchbrannten, der immer 
wieder mal mit markigen Bemerkungen Anstoss und Ärger erweckte, der sich aber nie zu schade war, wieder dafür zu schauen, dass die Auseinandersetzung nicht in einem Zerwürfnis endete, sondern einen Boden legte, auf dem man weiter um die Sache der Psychoanalyse streiten konnte. Für diese Haltung und diesen Umgang hat er meinen tiefen Dank. 